\title{
INTEGRATING TOPOGRAPHIC, PHOTOGRAMMETRIC AND LASER SCANNING TECHNIQUES FOR A SCAN-TO-BIM PROCESS
}

\author{
M. Lo Brutto ${ }^{1} *$, E. Iuculano ${ }^{1}$, P. Lo Giudice ${ }^{1}$ \\ ${ }^{1}$ Department of Engineering, University of Palermo, Italy \\ mauro.lobrutto@unipa.it; (emanuele.iuculano,paolo.logiudice)@community.unipa.it
}

\author{
Commission II, WG II/8
}

KEY WORDS: Laser scanner, UAV, Point cloud, 3D modeling, HBIM, Scan-to-BIM.

\begin{abstract}
:
The preservation of historic buildings can often be particularly difficult due to the lack of detailed information about architectural features, construction details, etc.. However, in recent years considerable technological innovation in the field of Architecture, Engineering, and Construction (AEC) has been achieved by the Building Information Modeling (BIM) process. BIM was developed as a methodology used mainly for new construction but, given its considerable potential, this approach can also be successfully used for existing buildings, especially for buildings of historical and architectural value. In this case, it is more properly referred to as Historic - or Heritage - Building Information Modeling (HBIM). In the HBIM process, it is essential to precede the parametric modeling phase of the building with a detailed 3D survey that allows the acquisition of all geometric information. This methodology, called Scan-to-BIM, involves the use of 3D survey techniques for the production of point clouds as a geometric "database" for parametric modeling. The Scan-to-BIM approach can have several issues relating to the complexity of the survey. The work aims to apply the Scan-to-BIM approach to the survey and modeling of a historical and architectural valuable building to test a survey method, based on integrating different techniques (topography, photogrammetry and laser scanning), that improves the data acquisition phase. The "Real Cantina Borbonica" (Cellar of Royal House of Bourbon) in Partinico (Sicily, Italy) was chosen as a case study. The work has allowed achieving the HBIM of the "Real Cantina Borbonica" and testing an approach based exclusively on a topographic constraint to merge in the same reference system all the survey data (laser scanner and photogrammetric point clouds).
\end{abstract}

\section{INTRODUCTION}

In the last years, technological innovation for the planning, management and preservation of buildings has been greatly enhanced by the BIM (Building Information Modeling) approach. The BIM is used to describe a collaborative process for the production and management of a building or facility asset during his entire life cycle, from planning to the demolition.

BIM was originally developed as a process mainly for the newbuild sector (building and infrastructure) but given the considerable innovation and benefits for the Architectural, Engineering and Construction (AEC) field it can also be successfully applied for existing buildings, especially for historic buildings. When the BIM process is applied to buildings of historical and architectural value, the process is called HBIM (Historic - or Heritage - Building Information Modeling). The HBIM process could be described as "a novel solution whereby interactive parametric objects representing architectural elements are constructed from historic data, these elements (including detail behind the scan surface) are accurately mapped onto a point cloud or image based survey" (Murphy et al., 2013).

The parametric model produced in the BIM process is not only a purely geometric representation of the building but a digital reconstruction of the object through the use of components equivalent to those used in reality (walls, floors, pillars, stairs, roofs, etc.). Building components, such as walls, floors, etc. are modelled as "smart objects"; they are able to be in connection with each other and are defined by numerical parameters, such as dimensions, but are also embedded with other kinds of information, such as building materials and properties (Pocobelli et al., 2018). The parametric model can also contain numerical data, for which there is no graphical representation (volumes, surfaces, etc..), but that it is possible to obtain and report in appropriate tables. All this information allows us to analyze the building in-depth (from the static, energy, etc.., point of view), in order to decide in a more adequate way the preservation and/or maintenance activities.

The role of BIM process does not end with the planning and construction phases, but rather continues during the entire life cycle of the building, during the management phase (facility management); in this phase, the economic resources necessary for the management of the building, especially if it is a historic building, can be quite high. This situation highlights the importance of applying the BIM process to historical buildings thanks to the development of HBIM, contributing to more effective and rational planning of maintenance operations.

For the implementation of a HBIM, however, it is necessary to precede the modeling phase with a $3 \mathrm{D}$ survey to acquire all the geometric data useful for the production of the as-built model of the building itself (Murphy et al., 2017). This approach is called Scan-to-BIM. The Scan-to-BIM involves the use of modern 3D survey techniques (3D laser scanning or photogrammetry) which allow the generation of point clouds used for the following parametric modeling phase (Wang et al, 2019). The Scan-to-BIM (i.e. the process of creating a parametric building information model from a point cloud) is one of the major challenge of HBIM but also a significant bottleneck in the process (Radanovic et al., 2020). In fact, in the Scan-to-BIM many issues may affect both the $3 \mathrm{D}$ survey phase and the parametric modeling phase. The dimensions and architectural complexity of the building, as well as the logistical situation, often condition the $3 \mathrm{D}$ survey; the

\footnotetext{
* Corresponding author
} 
unique and singular shapes of architectural elements and the lacking of appropriate parametric objects or "families" in the BIM software library could make modeling a difficult task.

For the 3D data acquisition, the integration of different surveying techniques is often essential to overcome logistical difficulties, especially when the objects to be surveyed are within historical city centres or are complex buildings.

Different survey "strategies" can be applied to obtain the 3D building data integrating different surveying techniques. 3D data can be obtained primarily by laser scanner surveying, using close-range photogrammetric surveying with an extendable telescopic pole for the roof (Bitelli et al., 2017). The 3D data acquisition of the interior of the building can be performed by laser scanning while the data of the exterior can be acquired with laser scanning and/or photogrammetric surveys by Unmanned Aerial Vehicle (UAV) (Rocha et al., 2020). In other cases, the inside part of the building can be surveyed using close-range photogrammetry by a fisheye camera, the external façade using laser scanning and the upper part of the building (the roof and other architectural elements not visible through the terrestrial survey) by UAV photogrammetry (Costantino et al., 2020). The internal and external survey can be also carried out using closerange photogrammetry and UAV photogrammetry (Themistocleous et al., 2019).

One of the most common problems in data acquisition during a Scan-to-BIM process is the need to connect the surveys carried out in the interior with those outside the building, especially in all those cases where openings or passageways between the interior and the exterior are limited (Murtiyoso and Grussenmeyer, 2018). Merging the point clouds generated for the interior with those obtained for the exterior is a very important step to ensure that the overall geometry of the building is rebuilt correctly.

The work aims to apply the Scan-to-BIM approach to the survey and modeling of a historical and architectural valuable building to test a survey method, based on integrating different techniques (topography, photogrammetry and laser scanning), that improves the data acquisition phase.

The "Real Cantina Borbonica" (Cellar of Royal House of Bourbon) in Partinico (Sicily, Italy), an architecture of great value built at the beginning of the 19th century, has been used as a case study. The survey of the "Real Cantina Borbonica" was carried out using a terrestrial laser scanner for the internal space and UAV photogrammetry for the outsides.

Some critical issues for the connection between the external and the internal environments allowed testing an approach based exclusively on a topographic constraint to merge in the same reference system all the survey data (laser scanner and photogrammetric point clouds). Even the laser scanner survey was carried out using a topographic approach. The 3D data were used to create a parametric model for the HBIM of the "Real Cantina Borbonica".

The activity was carried out within the Master Degree Laboratory "Scan-to-BIM: 3D survey for BIM process" of the University of Palermo with the main objective to exploit the use of integrated 3D survey techniques for the implementation of a complete HBIM workflow.

\section{CASE STUDY}

The "Real Cantina Borbonica" of Partinico was built by the orders of King Ferdinand I of Bourbon between 1800 and 1802. This building is recognized as an example of the advanced industrial architecture of the time; it was built both as a wine cellar but also as a centre for the storage and sale of food products.

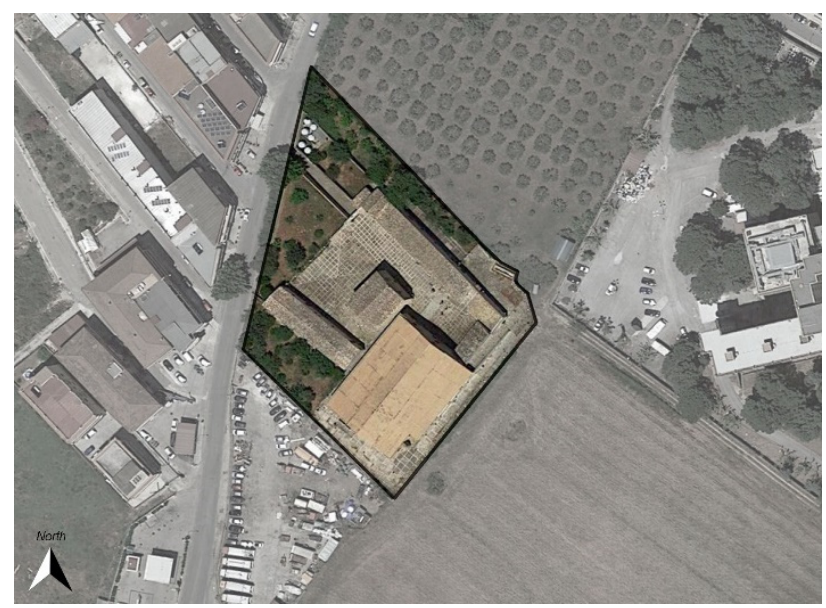

Figure 1. The "Real Cantina Borbonica" and the courtyard.

The "Real Cantina Borbonica" has a rectangular plan of about $1000 \mathrm{~m}^{2}$ and is located inside a large courtyard where there are some older buildings (Figure 1).

The "Real Cantina Borbonica" is composed of the main body plus a secondary part (on the southeast side) dating back to the building of the courtyard and therefore previous to the construction of the cellar. The construction of the main body of the cellar has probably eliminated a part of the previous buildings that were part of the ancient courtyard.

The "Real Cantina Borbonica" has also a large underground space, almost as big as the whole building, used to store wine; this space, however, was not included in the survey and modeling phases.

The entire main building is divided into three aisles supported by pillars and arches. The right and middle aisles are open (Figure 2 ), while the left aisle was closed off with a wall and used for the construction of wine vats and a millstone (Figure 3 ). The length of the "Real Cantina Borbonica" is about 36 meters, while its width is about 26 meters; the pillars are spaced approximately 5 $\mathrm{m}$ and $6 \mathrm{~m}$ in length and width respectively.

The structure of the "Real Cantina Borbonica" was built using large calcarenite blocks. These blocks, of unusual size compared to those used for normal building activities, were arranged in overlapping rows to obtain a remarkable solidity and stability of the walls. The gaps resulting from the imperfect squaring of the blocks were filled with mortar.

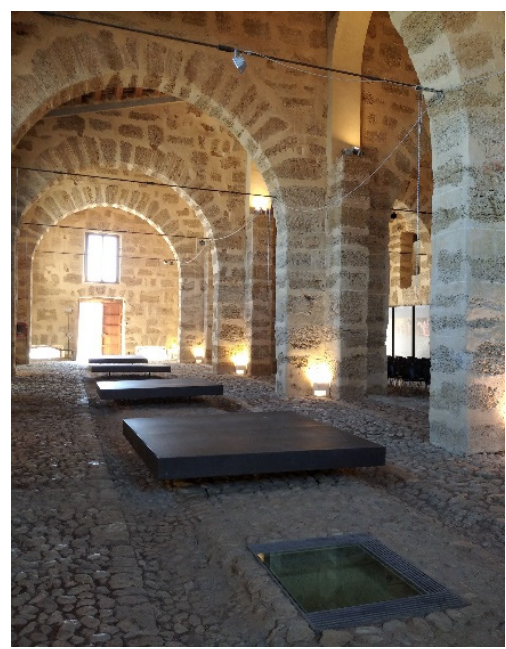

Figure 2. Interior of the "Real Cantina Borbonica": the right aisle. 


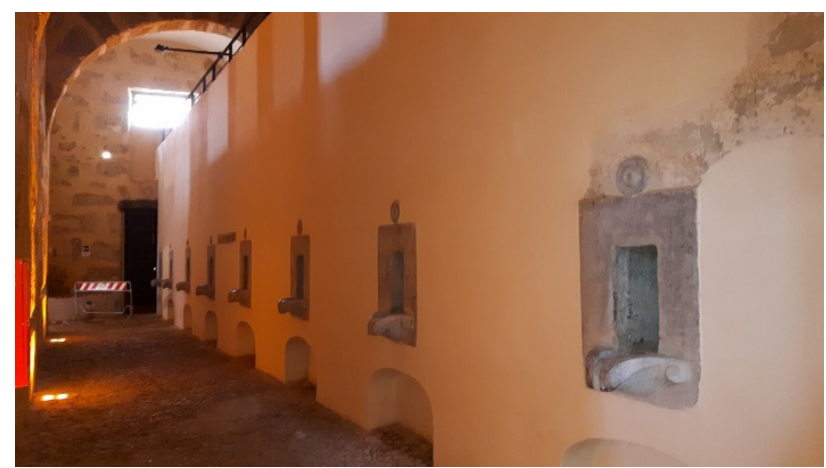

Figure 3. Interior of the "Real Cantina Borbonica": the left aisle with the wine vats.

The main façade of the "Real Cantina Borbonica" is characterized by the presence of three entrances that correspond to the three aisles of the building (Figure 4). The entrance in correspondence of the left aisle, however, has been obstructed by a structure added later. The main façade and the southwest façade have, in addition to the large windows, two large rose windows in the upper part.

The roof is made with two sloping pitches that have a height of $13.50 \mathrm{~m}$ in the roof ridge and a height of $8.70 \mathrm{~m}$ in the eaves line. From 2005 to 2007 the "Real Cantina Borbonica" was restored and transformed into an exhibition and conference hall.

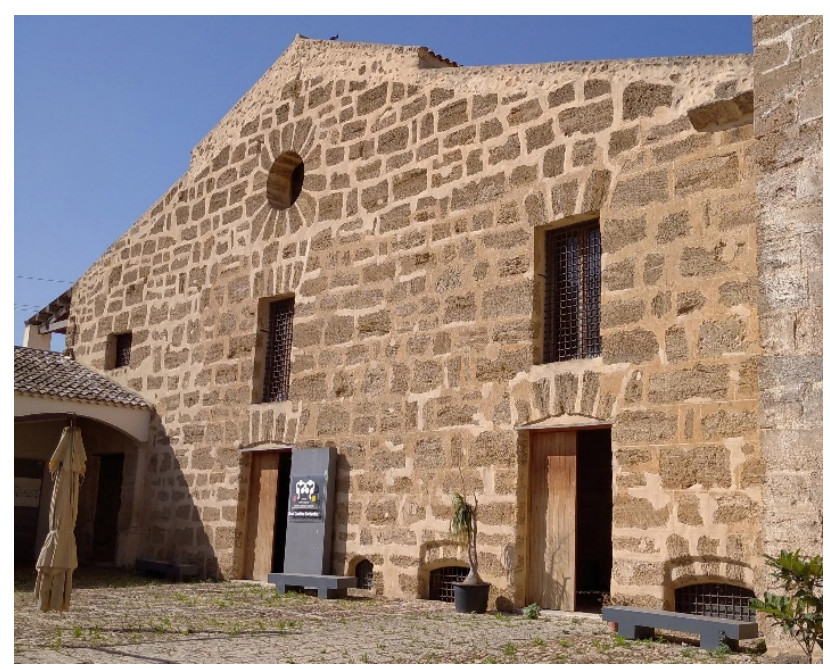

Figure 4. The main façade of the "Real Cantina Borbonica".

\section{DATA COLLECTION}

Before starting the survey phase, it was essential to evaluate which were the critical issues to be taken into account for the survey, which could be the most appropriate approach for the survey and which should be the level of detail of the point cloud. The most critical aspect of the survey was the connection between the internal and external environments. This connection could only be done through the two entrances in the main façade. The most suitable method was to use a topographic approach as a constraint to have all data in the same reference system. The result of the survey should be a point cloud with a resolution of less than 1 centimetre.

Data acquisition was planned by performing a laser scanning survey to acquire a point cloud of the interior environments and a UAV photogrammetric survey for a point cloud of external parts of the building; a topographic survey was also planned and aimed at measuring a closed topographic traverse on the outside of the building. The topographic traverse was measured with a Leica TPS 1105 total station and was made of 12 stations; the starting station and the orientation target were known points and were common with the laser scanner survey (Figure 5). The coordinates of the topographic traverse were calculated in a local reference system obtaining a root mean square (RMS) of \pm 2.2 $\mathrm{mm}$ for the planimetric coordinates and a RMS of $\pm 0.5 \mathrm{~mm}$ for the height component. The topographic traverse was used to define a common reference system for all data and to measure the Ground Control Points (GCPs) and the Check Points (CPs) for the photogrammetric survey.

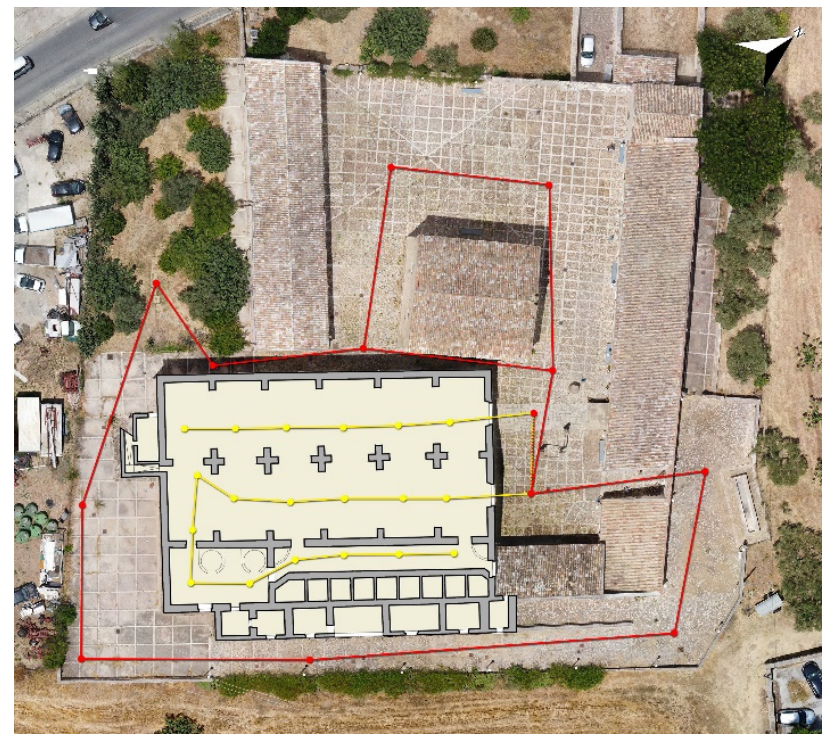

Figure 5. External topographic traverse (in red) and laser scanner traverse (in yellow).

\subsection{Laser scanner survey}

The laser scanner survey was executed using a topographic approach; all the scanning points were connected to form a topographic traverse. In particular, two scanning points were carried out outside the building at two vertices of the external traverse (Figure 5).

In this way, it was possible to connect all internal and external data by topographic measurements. The laser scanner survey was suitable to take advantage of the topographic approach, by the traverse method, provided by the Topcon GLS-2000 for scans registration (Ebolese et al., 2019; Ebolese and Lo Brutto, 2020). The Topcon GLS-2000 allows planning the scans along a traverse. The traverse method allows to set the point ("Occupation point") from which to perform the scan and from which to measure the previous scan point ("Backsight point") (Figure 6). Scans were automatically registered in a topographic way, even without large overlapping areas.

The method of using the laser scanner as a topographical instrument is commonly applied for scan registration if targets positioned on the building surface or algorithm for registration of common scan areas are not used (Bruno and Roncella, 2018). The topographic approach is not the only method to overcome problems of alignment between scans inside and outside buildings. The development of laser scanner devices that allow an alignment of the data already during the scanning phase allows optimizing the registration phase also using different approaches (Allegra et al., 2020).

A total of 21 scans were obtained along the traverse path with a full-dome field of view $\left(360^{\circ}\right.$ in the horizontal direction and $270^{\circ}$ in the vertical direction). A resolution of $6.3 \mathrm{~mm}$ at $10 \mathrm{~m}$ for the 
scans in right and middle aisles and with a resolution of $12.5 \mathrm{~mm}$ at $10 \mathrm{~m}$ for the scans in the left aisle was set. Some additional scans, not connected to the traverse, have been carried out on the wine vats in the left aisle to complete the survey of the internal part of the roof.

To complete the 3D survey of the "Real Cantina Borbonica", it was also necessary to scan the southeast side. This is composed of several rooms on the ground level not accessible from the main hall and an external upper porch (Figure 7).

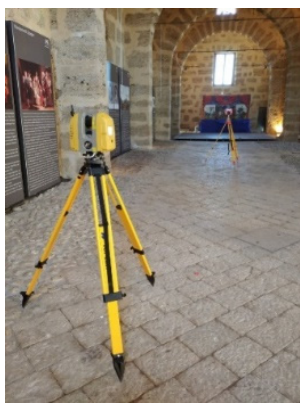

(a)

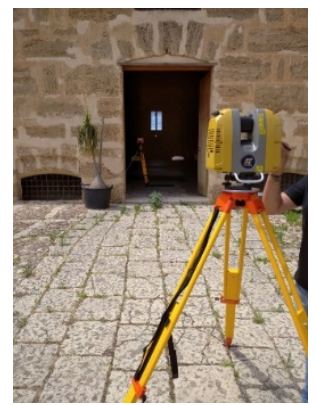

(b)
Figure 6. Laser scanner survey: inside (a) and outside acquisitions $(b)$.

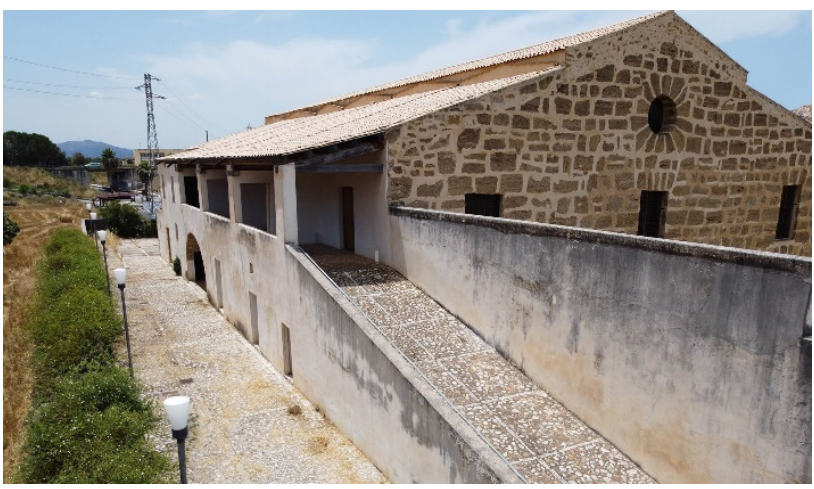

Figure 7. The southeast side of the "Real Cantina Borbonica".

The data acquisition of these spaces was carried out with a Faro Focus $120 \mathrm{~S}$ laser scanner applying a typical laser scanning methodology (several scans with a high percentage of overlap to ensure proper registration).

Thirteen scans were needed for the ground level rooms (Figure 8); twelve for the external upper porch. These scans were acquired with a full-dome field of view $\left(360^{\circ}\right.$ in the horizontal direction and $300^{\circ}$ in the vertical direction) and a resolution of about $12 \mathrm{~mm}$ at $10 \mathrm{~m}$.

The processing and the alignment of the scans collected with the GLS-2000 laser scanner were done with the Magnet Collage package by Topcon. With this package, it was possible to manage the data of the traverse laser scanner correcting the slight alignment errors that had occurred during the acquisition. Moreover, a semi-automatic cloud-to-cloud alignment was performed to connect the additional GLS-2000 scans to the traverse scans. A first point cloud of the interior has been obtained and exported in .e57 format to be merged with the other point clouds.

The Faro Focus scans were processed with the Autodesk Recap package. Two different projects were done: one for the scans of the ground level rooms and one for the scans of the external upper porch; so two different point clouds were obtained for the two parts.
The point cloud of the external upper porch was aligned and merged with the GLS-2000 point cloud from Magnet College using Autodesk Recap package.

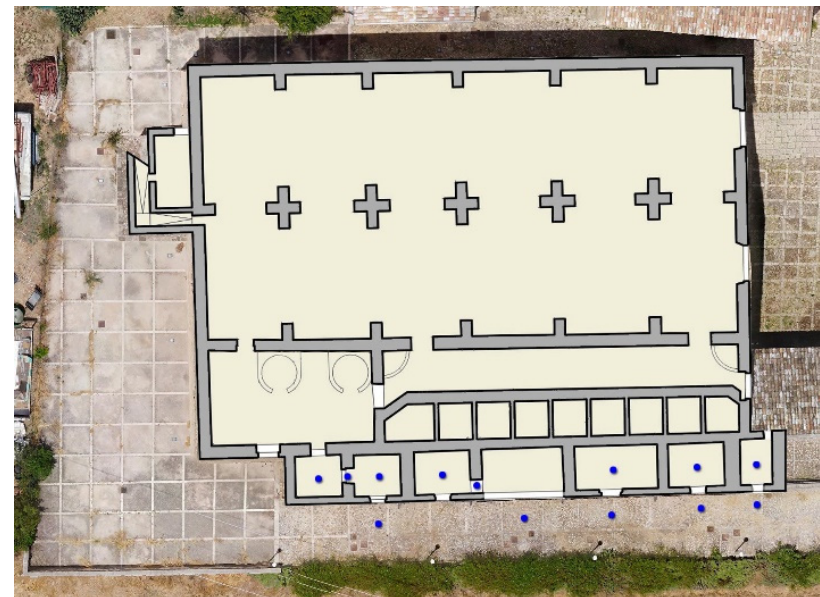

Figure 8. Scans positions (in blue) for the survey of the ground level rooms in the southeast side of the "Real Cantina Borbonica".

\subsection{Photogrammetric survey}

The photogrammetric survey was carried out using a UAV to survey all external parts of the building. A multi-rotor ultralightweight was used for image acquisition, which allowed flying over the study areas overcoming the restrictions imposed by UAV regulations. The use of ultra-lightweight UAVs is already quite widespread in the field of cultural heritage survey; several studies carried out with similar systems have shown the usefulness of these systems in different situations (Russo et al, 2018; Adami, 2019; Bakirman et al., 2020; Luhmann et al., 2020; Costantino et al., 2020).

The system used is the DJI Mavic Mini characterized by a weight of $249 \mathrm{~g}$ and a maximum flight duration of 30'; this system is equipped with a $1 / 2.3$ " CMOS sensor of $12 \mathrm{MP}$ with dimensions of $6.3 \mathrm{~mm} \times 4.7 \mathrm{~mm}$ that produces images of 4000 pixels $\times 3000$ pixels.

As in previous work where the UAV has been used for the 3D reconstruction of a historical building (Lo Brutto et al., 2018), different image configurations were used to survey the roof and façades: a nadiral flight to view the roof, two circular flights with an oblique camera for the roof and the façades, and flights with a parallel view of the façades (Figure 9).

The image acquisition was achieved with automatic flights using the Dronelink app for flight planning; only for the flights parallel to the façades, it was necessary to manually control the drone. Table 1 shows the main flight data of the survey.

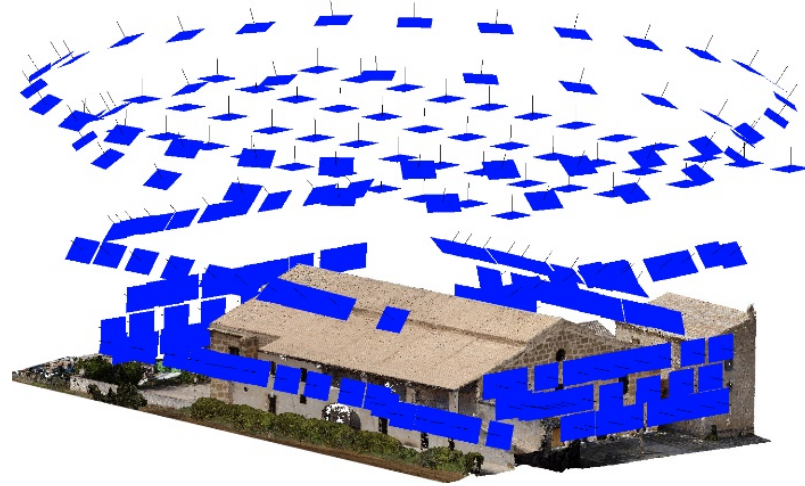

Figure 9. Scheme of UAV acquisition. 


\begin{tabular}{lcccc}
\hline \multicolumn{1}{c}{ Flight } & Images & $\begin{array}{c}\text { Altutude } \\
(\mathbf{m})\end{array}$ & $\begin{array}{c}\text { Distance } \\
(\mathbf{m})\end{array}$ & $\begin{array}{c}\text { GSD } \\
(\mathbf{m m})\end{array}$ \\
\hline Nadiral & 47 & 30 & $17 \div 21$ & $6.1 \div 7.5$ \\
Circular 1 & 21 & 30 & 35 & 12.5 \\
Circular 2 & 29 & 35 & 40 & 14.3 \\
Parallel & 150 & $2 \div 10$ & $5 \div 10$ & $1.8 \div 3.6$ \\
\hline
\end{tabular}

Table 1. Main flight data of the UAV survey.

The photogrammetric processing was executed using Agisoft Metashape according to three main steps: the "Image alignment" or Structure from Motion, to determine the initial exterior orientation and camera calibration parameters, the "Optimization" or Bundle Block Adjustment, to calculate the exterior orientation parameters and to improve the estimation of camera calibration parameters and the Dense Image Matching, to finally reconstruct the dense point cloud. "Image alignment" parameters were set high for "Accuracy", with a key point limit of 40000 and a tie point limit of 4000; "Optimization" was carried out estimating a camera model with three radial distortion parameters and two tangential distortion parameter. 32 GCPs were used for the exterior orientation and $29 \mathrm{CPs}$ to evaluate the photogrammetric accuracy. The mean re-projection error was 0.7 pixel; the RMS in object space for the GCPs was $\pm 1.7 \mathrm{~cm}$, while for the CPs $\pm 1.5 \mathrm{~cm}$. The dense point cloud generation was achieved setting a high "Quality" in Methashape.

\subsection{Point cloud of the "Real Cantina Borbonica"}

The survey allowed us to obtain an overall point cloud of the building from two perfectly superimposable point clouds; one of the interior by laser scanner survey and one of the exterior by UAV survey. The two point clouds have been overlapped and merged simply according to their coordinates. Visual inspection was performed throughout the point cloud, along horizontal and vertical sections to check the joining process. The inspection has not highlighted rotation between the two point clouds or anomalies in wall thicknesses. After this check, the laser scanner point cloud of the southeast side ground level rooms was also merged with this new point cloud, through a cloud-to-cloud registration.

A point cloud with more than 600 million points was obtained after merging (Figure 10); this dataset had too much resolution and was very difficult to handle. Therefore, the point cloud was sub-sampled using CloudCompare software and the "spatial mode", setting a minimum distance between two points of $7 \mathrm{~mm}$. The final point cloud for the parametric model production was obtained with about 170 million points.

\section{THE HBIM OF THE "REAL CANTINA BORBONICA"}

The overall point cloud was used for the parametric modeling in the BIM environment using Revit package by Autodesk. Each architectural element of the building was reconstructed as a parametric element using the information from the point cloud. Parametric modeling of architectural elements was not so simple as many elements often had unique shapes that typical BIM libraries do not include (Allegra et al., 2020). In the field of HBIM and Scan-to-BIM, the connection between information and complex geometric entities are not always easy due to the lack of advanced modeling tools in BIM applications (Banfi, 2020).

The point cloud was managed with Recap and converted in .rcp format for the importing in Revit. The point cloud was inserted into Revit keeping its position within the reference system used for the survey.

Revit, like other BIM software, allows to build "smart objects", which are called families; a family is defined as a group of elements with a set of common properties called parameters and an associated graphical representation. There are three main types of families in Revit: system families, which cannot be created but only modified, for example walls, floors and roofs are system families; loadable families, these families can be generated independently and then can be loaded into any project, in this way it is possible to create families even with a high level of geometric definition; in-place families, these families are similar to loadable families but with the only difference that they refer to a single project and have been generated directly on the model.
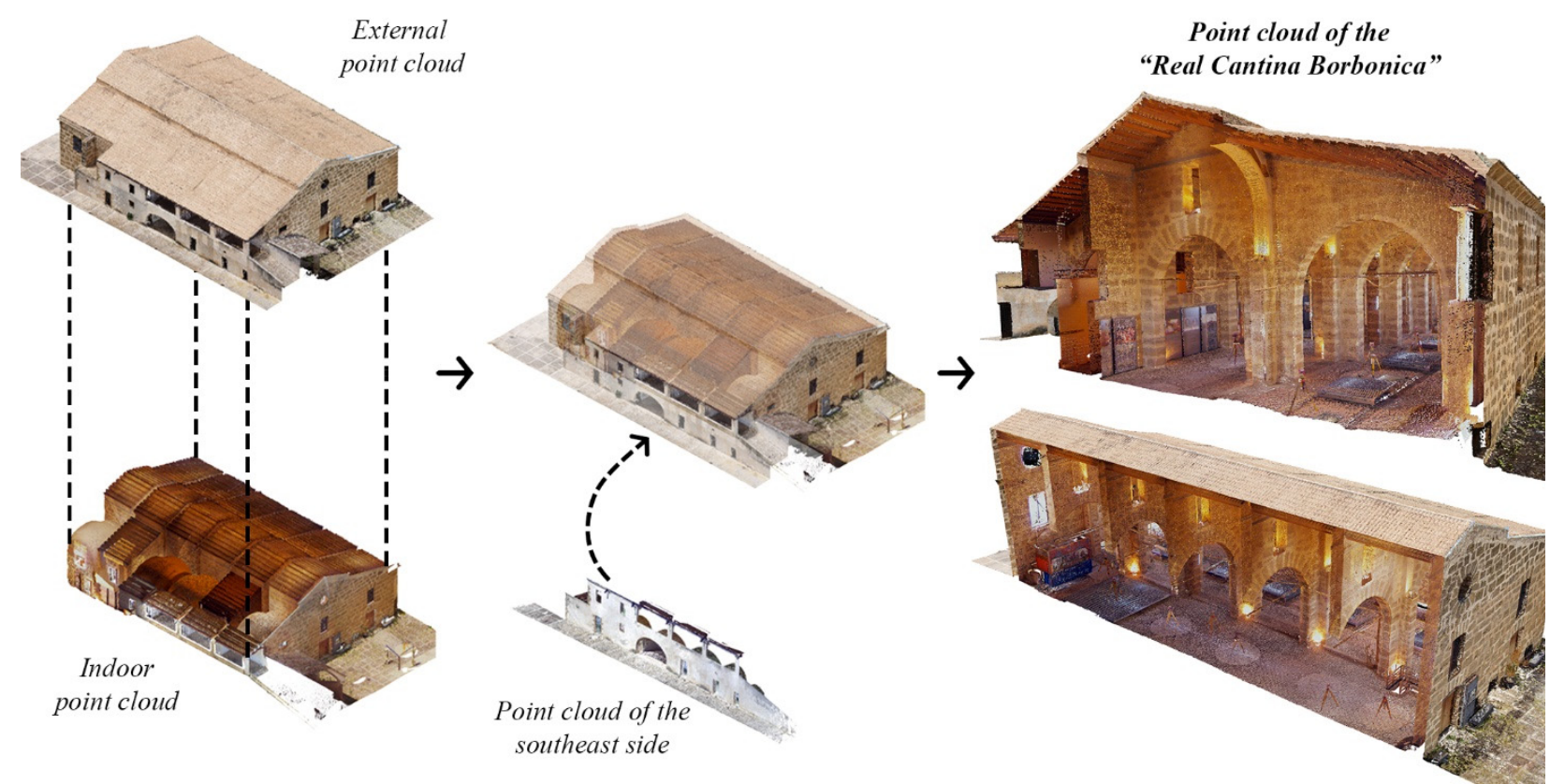

Figure 10. Point cloud of the "Real Cantina Borbonica". 
To begin the modeling phase all the working views, both vertical and horizontal, which are useful for the construction of the HBIM model, were set up. The reconstruction of the parametric model started with the identification of the main elements of the structure; in particular, it has been chosen to model first the perimeter walls then the internal ones. Using some sections, wall models were re-built following the outline of the point cloud. This method requires a considerable amount of work but it is very accurate because it traces the real size and position of the object. In this way, a real plan of the building, in which it is possible to quantify the thickness of the walls, was obtained.

To build the large arches in the main space, a wall was first created and then modified using the point cloud as a reference by generating a void with the shape of the arch. During the modeling it was noticed that the arches of the main structure had the same dimensions; so this process was done in the same way for all the arches. The result was the creation of arches in the wall structure (Figure 11). The same procedure has been performed for all openings in the walls where there is no presence of door frames.
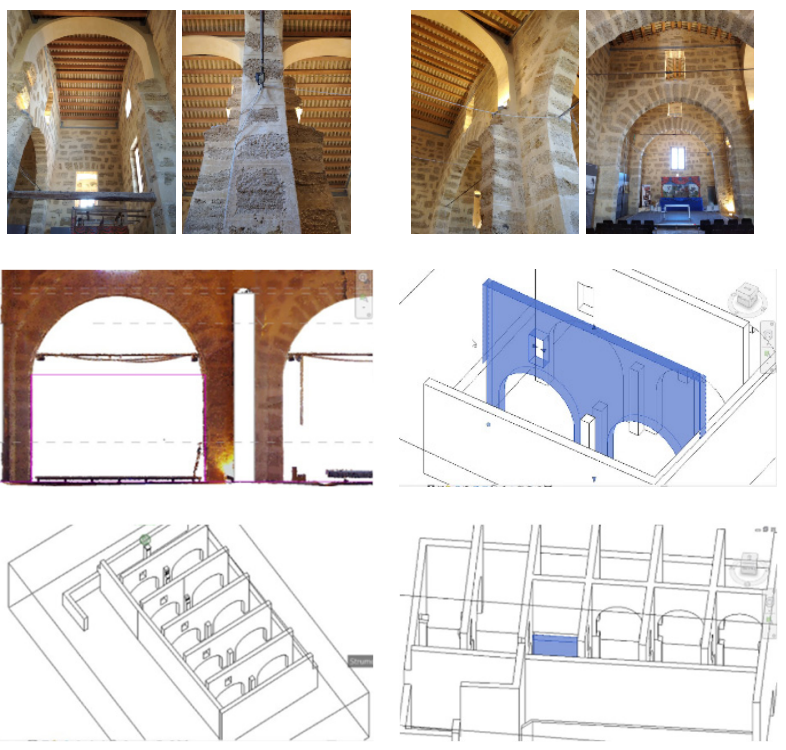

Figure 11. Parametric modeling of the large arches.

The floors were made using the Revit tools; for the ground floor an arbitrary thickness of $50 \mathrm{~cm}$ was chosen while the other floors were realized with their actual thickness.

BIM software is designed for new construction, so many architectural elements needed in model creation do not exist. For this reason, new families have been created for some architectural elements such as doors, windows and vaults.

All doors and windows were modelled by creating "loadable families" getting the effective dimensions from the point cloud. Details such as shutters and frames have been defined; in some cases, as for the main entrance door, it has been necessary to add wooden lintels above the door and small arches above the lintel (Figure 12).

An adaptive Revit component was used to create the vaults. This allowed creating the barrel vaults with their actual geometry. The cross vaults were generated within the project using the "in-place mass" tool.

The coverage of the "Real Cantina Borbonica" is characterized by a system of wooden beams, positioned orthogonally to the main facades, which supports the roof. Before creating the system of beams it was necessary to create the profile of the roof and the various pitches of the roof with the right inclination. This task was very problematic due to the very irregular perimeter of the building. Then an internal beam system was created (Figure 13).

After the parametric model was completed, it was possible to obtain the most useful 2D representations such as plans or longitudinal and cross-sections. In addition, the $3 \mathrm{D}$ views were obtained by inserting some elements (doors, windows) with realistic colours (Figure 14).

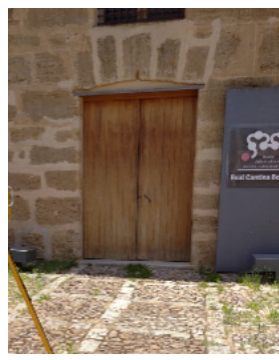

(a)

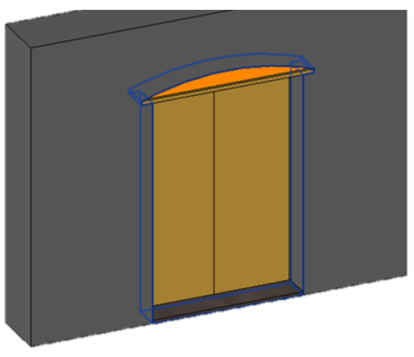

(b)
Figure 12. The modeling of the main entrance door: the real door (a), the parametric model (b).

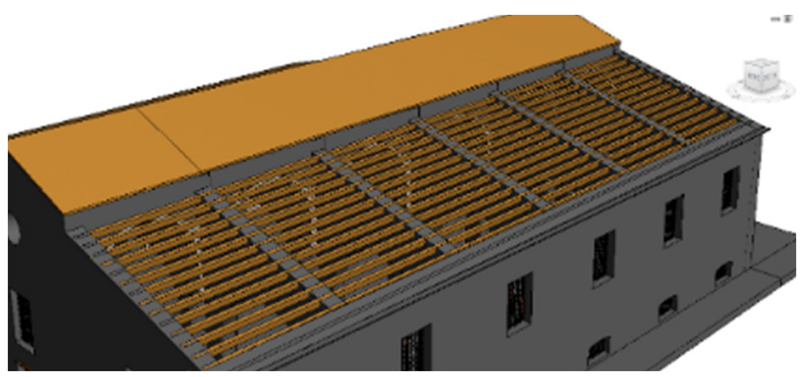

Figure 13. The parametric model of the coverage of the "Real Cantina Borbonica".

\section{CONCLUSIONS}

The work has shown that the Scan-to-BIM approach provides excellent results for the development of HBIM models, but some critical issues make this approach particularly challenging.

The proposed method of integrating techniques for the survey, in particular for laser scanning surveying, even if limited by the use of devices with specific characteristics, was proven to be particularly effective in solving a problem that frequently occurs in situations such as the one proposed; this approach could therefore be considered as an example for similar work.

The parametric modeling highlighted some critical issues such as the problem of managing large amounts of data (the final point cloud reached more than 100 million points) and the need to create new parametric families for some architectural elements. These aspects affected processing times but have nevertheless solved by implementing ad-hoc procedures.

\section{ACKNOWLEDGEMENTS}

The research activity was carried out within the Master degree laboratory "Scan-to-BIM: 3D survey for BIM modeling". The authors are grateful to the Municipality of Partinco that allowed carrying out the surveys, and to Topcon Positioning Italy, in particular to Mario Fucile, for providing the laser scanner GLS2000 and for support in the acquisition and processing phase. 

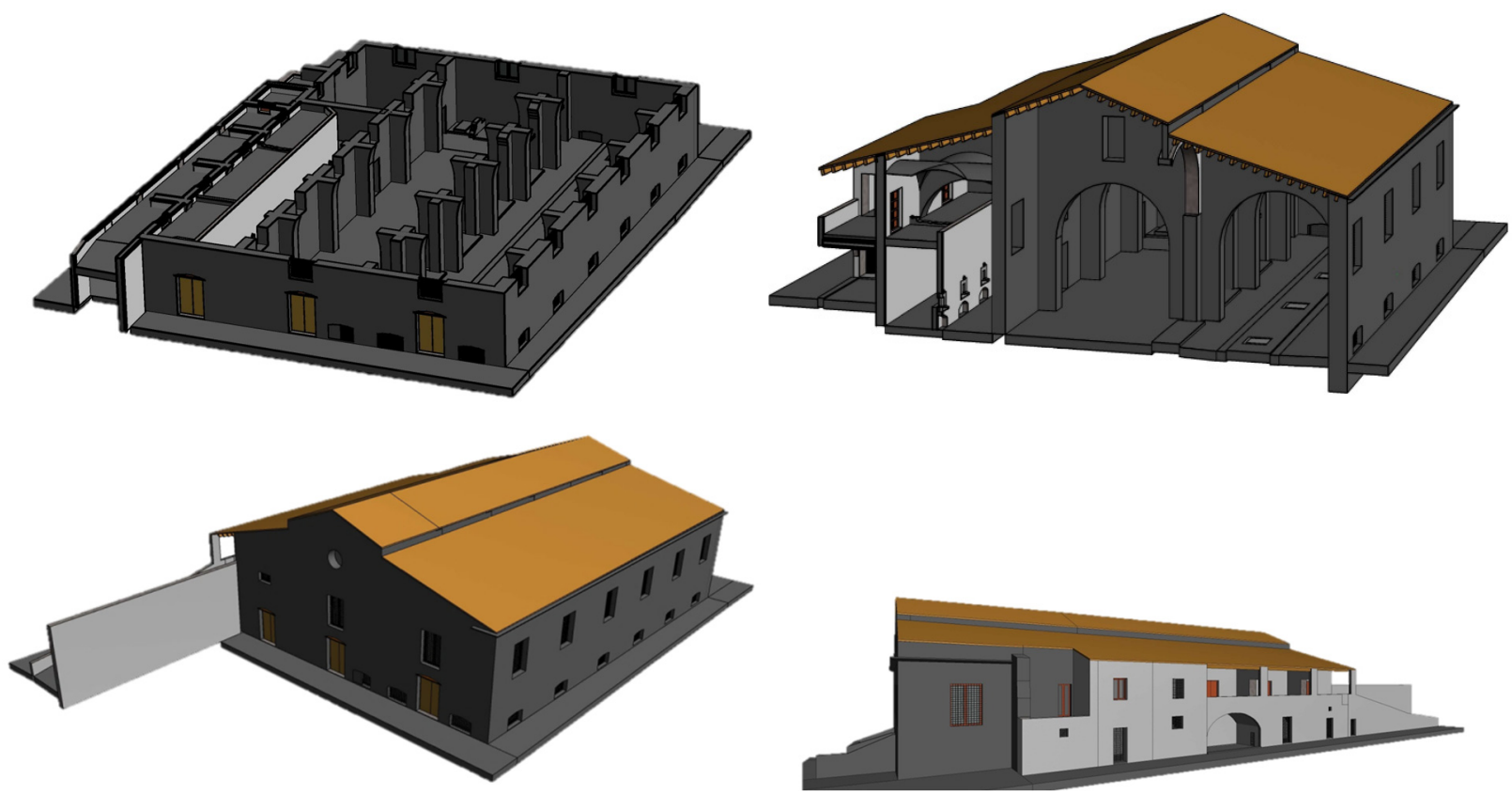

Figure 14. HBIM of the "Real Cantina Borbonica": 3D views of the parametric model.

\section{REFERENCES}

Adami, A., Fregonese, L., Gallo, M., Helder, J., Pepe, M., Treccani, D., 2019. Ultra light UAVsystems for the metrical documentation of Cultural Heritage: applications for architecture and archaeology. Int. Arch. Photogramm. Remote Sens. Spatial Inf. Sci., XLII-2/W17, 15-21, https://doi.org/10.5194/isprsarchives-XLII-2-W17-15-2019

Allegra, V., Di Paola, F., Lo Brutto, M., and Vinci, C., 2020. Scan-to-BIM for the management of Heritage Buildings: The case study of the Castle of Maredolce (Palermo, Italy), Int. Arch. Photogramm. Remote Sens. Spatial Inf. Sci., XLIII-B2-2020, 1355-1362. https://doi.org/10.5194/isprs-archives-XLIII-B22020-1355-2020

Bakirman, T., Bayram, B., Akpinar, B., Karabulut, M.F., Bayrak, O.C., Yigitoglu, A., Seker, D.Z., 2020. Implementation of ultralight UAV systems for cultural heritage documentation. Journal of Cultural Heritage, 44, 174-184. https://doi.org/10.1016/j.culher.2020.01.006

Banfi, F., 2020. HBIM, 3D drawing and virtual reality for archaeological sites and ancient ruins. Virtual Archaeology Review, 11, 23, 16-33. https://doi.org/10.4995/var.2020.12416.

Bitelli, G., Dellapasqua, M., Girelli, V., Sanchini, E., Tini, M., 2017. 3D Geomatics Techniques for an integrated approach to Cultural Heritage knowledge: The case of San Michele in Acerboli's Church in Santarcangelo di Romagna. Int. Arch. Photogramm. Remote Sens. Spat. Inf. Sci., XLII-2, 291-296. https://doi.org/10.5194/isprs-archives-XLII-5-W1-291-2017

Bruno, N., Roncella, R. A, 2018. Restoration oriented HBIM system for Cultural Heritage documentation: The case study of Parma cathedral. Int. Arch. Photogramm. Remote Sens. Spat. Inf. Sci., XLII-2, 171-178. https://doi.org/10.5194/isprs-archivesXLII-2-171-2018
Costantino, D., Pepe, M., Restuccia, A., 2021. Scan-to-HBIM for conservation and preservation of Cultural Heritage building: the case study of San Nicola in Montedoro church (Italy). Applied Geomatics, Published online: 28 January 2021. https://doi.org/10.1007/s12518-021-00359-2

Ebolese, D., Lo Brutto, M., Dardanelli, G., 2019. The integrated 3D survey for underground archaeological environment. Int. Arch. Photogramm. Remote Sens. Spatial Inf. Sci., XLII-2/W9, 311-317, https://doi.org/10.5194/isprs-archives-XLII-2-W9$311-2019$

Ebolese, D., Lo Brutto, M., 2020. Study and 3D survey of the Roman baths in the archaeological site of Lylibaeum (Marsala, Italy). IOP Conference Series: Materials Science and Engineering, 949, 012103. https://doi:10.1088/1757899X/949/1/012103

Lo Brutto, M., Ebolese, D., Dardanelli, G., 2018. 3D modelling of a historical building using close-range photogrammetry and Remotely Piloted Aircraft System (RPAS). Int. Arch. Photogramm. Remote Sens. Spatial Inf. Sci., XLII-2, 599-606, https://doi.org/10.5194/isprs-archives-XLII-2-599-2018.

Luhmann, T., Chizhova, M., Gorkovchuk, D., 2020. Fusion of UAV and Terrestrial Photogrammetry with Laser Scanning for 3D Reconstruction of Historic Churches in Georgia. Drones, 4, 53. https://doi.org/10.3390/drones4030053

Murtiyoso, A., Grussenmeyer, P., 2018. Comparison and assessment of 3D registration approaches of point clouds in the case of exterior and interior heritage building recording. Int. Arch. Photogramm. Remote Sens. Spatial Inf. Sci., XLII-2, 745751, https://doi.org/10.5194/isprs-archives-XLII-2-745-2018

Murphy, M., McGovern, E., Pavia, S., 2013. Historic Building Information Modelling - Adding intelligence to laser and image based surveys of European classical architecture. ISPRS Journal 
of Photogrammetry and Remote Sensing, 76, 89-102. https://doi.org/10.1016/j.isprsjprs.2012.11.006

Murphy, M., Corns, A., Cahill, J., Eliashvili, K., Chenau, A., Pybus, C., Shaw, R., Devlin, G., Deevy, A., and Truong-Hong, L., 2017. Developing historic building information modelling guidelines and procedures for architectural heritage in Ireland. Int. Arch. Photogramm. Remote Sens. Spatial Inf. Sci., XLII2/W5, 539-546, https://doi.org/10.5194/isprs-archives-XLII-2W5-539-2017.

Pocobelli, D.P., Boehm, J., Bryan, P., Still, J., Grau-Bové, J., 2018. BIM for heritage science: a review. Heritage Science, 6, 30, 1-15. https://doi.org/10.1186/s40494-018-0191-4

Radanovic, M., Khoshelham, K., Fraser, C., 2020. Geometric accuracy and semantic richness in heritage BIM: A review. Digital Applications in Archaeology and Cultural Heritage, 19, e00166, 1-11. https://doi.org/10.1016/j.daach.2020.e00166

Rocha, G., Mateus, L., Fernández, J., Ferreira, V., 2020. A Scanto-BIM Methodology Applied to Heritage Buildings. Heritage, 3(1), 47-67. https://doi.org/10.3390/heritage3010004

Russo, M., Carnevali, L., Russo, V., Savastano, D., Taddia, Y., 2019. Modeling and deterioration mapping of façades in historical urban context by closerange ultra-lightweight UAVs photogrammetry. International Journal of Architectural Heritage, 13:4, 549-568, DOI: 10.1080/15583058.2018.1440030

Themistocleous, K., Mettas, C., Evagorou, E., Hadjimitsis, D., 2019. The use of UAVs and photogrammetry for the documentation of cultural heritage monuments: the case study of the churches in Cyprus. In: Proc. SPIE 11156, Earth Resources and Environmental Remote Sensing/GIS Applications X, 111560I (3 October 2019). https://doi.org/10.1117/12.2533056

Wang, Q., Guo, J., Kim, M.-K., 2019. An Application Oriented Scan-to-BIM Framework. Remote Sensing, 11(3), 365, 2-27. https://doi.org/10.3390/rs11030365 